\title{
Analysis of Low-Altitude Inversion Characteristics of Coal-Fired Power Projects Based on Tethered Balloon Observation
}

\author{
Xuejiao Gao1, Yue Bai'2, Hongwei Tian1, Fei Ju3 \\ ${ }^{1}$ Yulin City Meteorological Bureau of Shaanxi Province, Yulin, China \\ ${ }^{2}$ West Airport Group Yulin Airport Co. Ltd., Yulin, China \\ ${ }^{3}$ Shaanxi Provincial Meteorological Observatory, Xi'an, China \\ Email: sxylqxgxj@sina.com
}

How to cite this paper: Gao, X. J., Bai, Y., Tian, H. W., \& Ju, F. (2019). Analysis of Low-Altitude Inversion Characteristics of Coal-Fired Power Projects Based on Tethered Balloon Observation. Journal of Geoscience and Environment Protection, 7, 244-252.

https://doi.org/10.4236/gep.2019.711018

Received: October 23, 2019

Accepted: November 26, 2019

Published: November 29, 2019

Copyright (c) 2019 by author(s) and Scientific Research Publishing Inc. This work is licensed under the Creative Commons Attribution International License (CC BY 4.0).

http://creativecommons.org/licenses/by/4.0/

\begin{abstract}
Atmospheric inversion phenomenon directly affects the vertical movement of air, which causes the cooling heat of the cooling tower in the power plant to be blocked. Therefore, it is necessary to analyze the atmospheric inversion characteristics of the research project during the design of the air cooling system. Using the low-altitude observing system of the tethered balloon, the on-site observation of the temperature below $300 \mathrm{~m}$ in summer is carried out for a coal-fired power integration project in Yulin, Shaanxi, China. Observations were made at 10 fixed times per day, with a cumulative observation of 46 days and 247 effective detections. The data were quality-controlled, and then linearly interpolated. According to the requirements of the project designer, the temperature data of 20,50,100,150,200,250, $300 \mathrm{~m}$ was used for low-temperature inversion analysis. The research shows that the grounding inversion and low-altitude inversion can be observed at the same time. In the time and space changes, the grounding inversion temperature and intensity are significantly higher than the low-altitude inversion. The maximum inversion of grounding inversion and low-altitude inversion is $2.3^{\circ} \mathrm{C} / \mathrm{hm}$, $1.0^{\circ} \mathrm{C} / \mathrm{hm}$. Grounding inversion temperature occurs every time, the frequency is the highest at 20 o'clock, the average intensity is maximum at 17 o'clock, and the average height, maximum intensity and maximum height are maximum at 7 o'clock. When the low-altitude inversion temperature is 18 o'clock, other times can occur, and the frequency is the highest at 15 o'clock, but the inversion layer is shallow, the bottom is high and the intensity is small. Grounding inversion and low-altitude inversion can occur in all levels, and as the height increases, the grounding inversion decreases and the low-temperature inversion increases. The design of the project air
\end{abstract}


cooling tower needs to fully consider the impact caused by the inverse temperature below $300 \mathrm{~m}$.

\section{Keywords}

Low-Altitude Detection, Inverse Temperature, Air Cooling Tower Design

\section{Introduction}

In the coal-fired power project, the air-cooling system uses air as the cold end of the steam turbine of the thermal power plant, cooling the steam from the steam turbine unit, condensing the spent steam in the low-pressure cylinder of the steam turbine into condensed water, and returning it to the boiler cycle. Complete a work cycle and proceed to the next work cycle. The cooling efficiency of power plants cooled by air cooling is closely related to environmental meteorological elements. The statistical characteristics of environmental meteorological factors are the necessary parameters for the design of cooling systems. For power generation projects using indirect air cooling, the cooling tower suction between the natural ventilation indirect air cooling system is provided by the inlet and outlet air temperature difference. The atmospheric inversion phenomenon directly affects the vertical movement of the air, causing the cooling tower to be blocked and naturally ventilated. The pumping force is reduced, which in turn affects the cooling effect of the air cooling tower. Therefore, it is necessary to analyze the atmospheric inversion characteristics of the research project when designing the air cooling system.

Many scholars have applied meteorological sounding data to analyze the inversion characteristics of urban and regional atmospheres and their effects on atmospheric diffusion (Shen et al., 2011; Wang, 2014; Zhou et al., 2015; Li et al., 2011). There are also many scholars who use tethered balloons to conduct atmospheric research. Wylie \& Young (1979) studied the convection of strong winds on Lake Michigan and studied the changes in the atmospheric boundary layer caused by the interaction with the cold water surface. Alsamhi et al. (2018) used the tethered balloon technique to solve the problem of connecting wireless communication networks in field experiments. Yabuki et al. (2016) used a tethered balloon to observe the temporal and spatial distribution of water vapor and cooperates with the lidar. However, the above research combined with power plant projects is relatively rare.

In order to effectively reflect the low-altitude inversion characteristics of the coal-electricity integrated project power plant (hereinafter referred to as coal-fired power project), on-site sounding observation is required. According to the field observation data, the in-depth intensity, inversion height and inversion time law of the project below $300 \mathrm{~m}$ are comprehensively analyzed. The research results are used as the scientific basis for the design of the selected 
air-cooling system and the relevant parameters, which can be used by the design unit.

\section{Data and Methods}

\subsection{Source of Detection Data}

The coal-fired power project is located in a coal mine area northeast of Dianta Town, Shenmu City. The project is based on the "coal-electricity integration" model and a new $2 \times 660 \mathrm{MW}$ ultra-supercritical indirect air-cooled coal-fired unit. According to the plan of Shaanxi West Power East to send coal power base, the construction of the Shaanbei-Wuhan $\pm 800 \mathrm{kV}$ UHV DC transmission project is planned in Shensu Mining Area. The project is located in the North Shaanxi Coal and Electricity Base as one of the alternative power points for DC delivery. The power generated by the State Grid Corporation and Shaanxi Province's "13th Five-Year Plan" of the "Shaanbei-Wuhan" UHV DC transmission line was sent to Hubei and Central China for consumption, realizing the local conversion of resources and transforming coal into power transmission. National energy industry policy.

The project site is located in the valley, and the flat area suitable for the application of the airship is selected as the observation point. The surrounding area is a gentle slope with relatively small changes in relative elevation, which can more accurately reflect the changes in meteorological elements observed in the near-surface layer of the site. After strict site selection, the coordinates of the low-altitude detection site (detailed information omitted) are determined and fixed-point observations are performed.

\subsection{Technical Methods}

Low temperature detection using a tethered balloon low-altitude observation system consisting of four parts: a balloon, a sonde, a microprocessor, and a winch. The detection system has high measurement accuracy, low cost, simple operation, convenient movement and reusability, and is an intuitive system for detecting low-level structures of the atmosphere.

The observation period is from July 16th to August 31st, 2018, totaling 46d, and 247 effective detections are completed. All monitoring data is transmitted to the ground receiving end every $6 \mathrm{~s}$. The detection height is $300 \mathrm{~m}$, and the airship is applied from the near ground to about $320 \mathrm{~m}$, ensuring continuous observation of temperature data below $300 \mathrm{~m}$. The detection is performed 10 times a day at $7,9,11,14,15,16,17,18,19,20$ o'clock, respectively.

Quality control is performed on all collected data, and unreasonable data is eliminated. A linear interpolation method is used to generate a two-dimensional temperature data set by time and height. The air temperature data of 20, 50, 100, $150,200,250,300 \mathrm{~m}$ from the ground is used to analyze the low temperature inversion characteristics below $300 \mathrm{~m}$.

According to the position of the inversion layer, it can be divided into grounded 
inversion and low-altitude inversion. The grounding inversion is the inversion of the inversion layer in contact with the ground. Low-altitude inversion refers to the inversion from a certain height from the ground, that is, the inversion at a certain height from the ground, which may have one or more layers. The elements characterizing the inversion characteristics are the bottom height, top height, thickness and inversion strength of the inversion layer. Since the amount of data collected under $20 \mathrm{~m}$ is small, there is no statistical analysis significance. Therefore, in this project, the bottom height of the grounding inversion is $20 \mathrm{~m}$, and the bottom height of the low-temperature inversion is greater than or equal to $50 \mathrm{~m}$.

\section{Results and Discussion}

\subsection{Characteristics of Vertical Temperature Change and Inversion of Daily Temperatures}

The 247 effective observation data were analyzed, and the average temperature at different altitudes was calculated. The temperature ranged from $21.9^{\circ} \mathrm{C}$ to $31.5^{\circ} \mathrm{C}$, and the highest average temperature appeared at 17 o'clock near the ground ( $20 \mathrm{~m}$ from the ground), and the lowest average temperature was near the ground at 7 o'clock.

The average temperature profile is drawn. It can be seen from Figure 1 that the grounding inversion temperature is formed at 20 to $100 \mathrm{~m}$ at 20 o'clock, and the inversion temperature is $0.6^{\circ} \mathrm{C} / \mathrm{hm}$. At 7 o'clock, the grounding inversion temperature appeared at $20-200 \mathrm{~m}$, the inversion temperature was $0.2^{\circ} \mathrm{C} / \mathrm{hm}$; 250 - $300 \mathrm{~m}$ was shallow and low temperature inversion, and the inversion temperature was $0.2^{\circ} \mathrm{C} / \mathrm{hm}$. As the solar radiation increases, the near-surface temperature begins to rise. At the same time, the convective activity in the surrounding area of the project site is strong in summer. The vertical movement of the air breaks through the inversion layer, and the upper and lower layers of the air exchange heat, and the inversion layer begins to weaken to the isothermal layer. There is no inversion layer at $9-19$ o'clock, but there is an isothermal layer at 9:20 to $50 \mathrm{~m}, 18: 20$ to $50 \mathrm{~m}$, and 20 o'clock to $100-150 \mathrm{~m}$.

\subsection{Inversion Temperature Variation Characteristics}

It can be concluded from Figures 2-4 that the grounding inversion temperature occurs every time, the frequency is $10.5 \%-71.9 \%$, the average intensity is 0.4 $1.1^{\circ} \mathrm{C} / \mathrm{h}$, the average top height is $58.3-194.1 \mathrm{~m}$, and the maximum intensity is $2.3^{\circ} \mathrm{C} / \mathrm{hm}$. The top height is $300 \mathrm{~m}$. The frequency is the highest at $20 \mathrm{o}^{\prime} \mathrm{clock}$ and the average intensity at 17 o'clock. At 7 o'clock, the average height, maximum strength and maximum height reached the maximum values of $194.1 \mathrm{~m}$, $2.3^{\circ} \mathrm{C} / \mathrm{hm}$ and $300 \mathrm{~m}$, respectively. On average, the change in grounding inversion height, intensity and top height reflects the change characteristics of grounding inversion temperature, which is generated and enhanced after sunset, and gradually weakens after sunrise. 

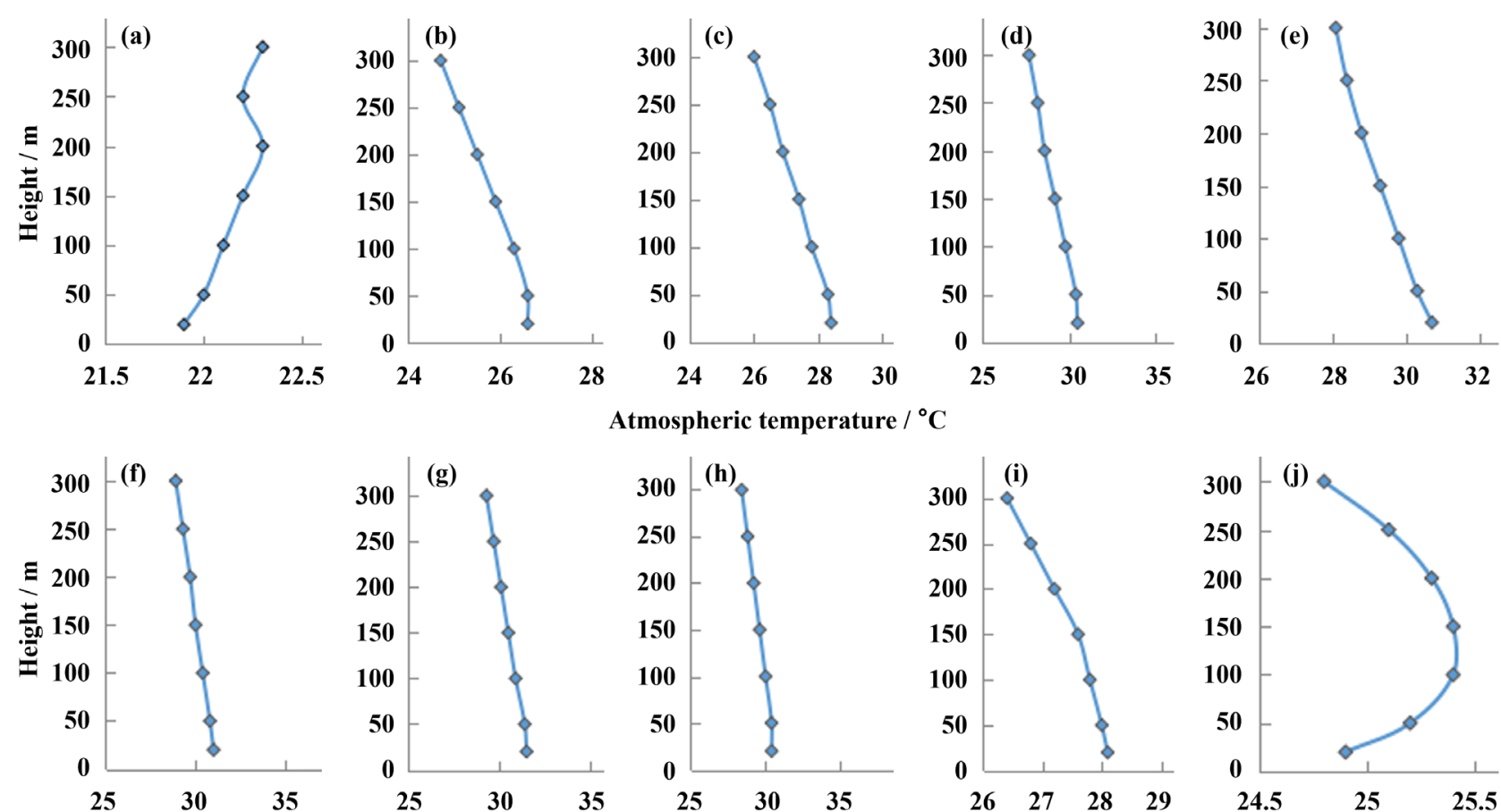

Atmospheric temperature $/{ }^{\circ} \mathrm{C}$
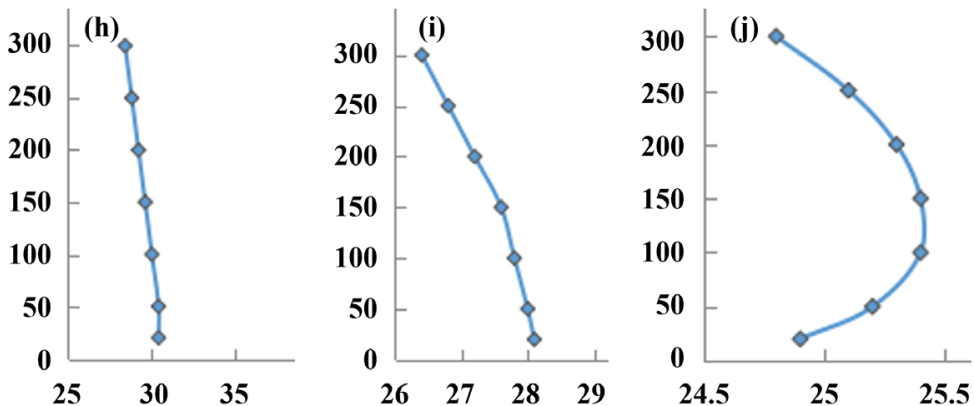

Atmospheric temperature $/{ }^{\circ} \mathrm{C}$

Figure 1. Average temperature profile at each time from 20 to $300 \mathrm{~m}$ (a. at 7 o'clock; b. at 9 o'clock; c. at 11 o'clock; d. at 14 o'clock; e. at 15 o'clock; f. at 16 o'clock; g. at 17 o'clock; h. at 18 o'clock; i. at 19 o'clock; j. at 20 o'clock).

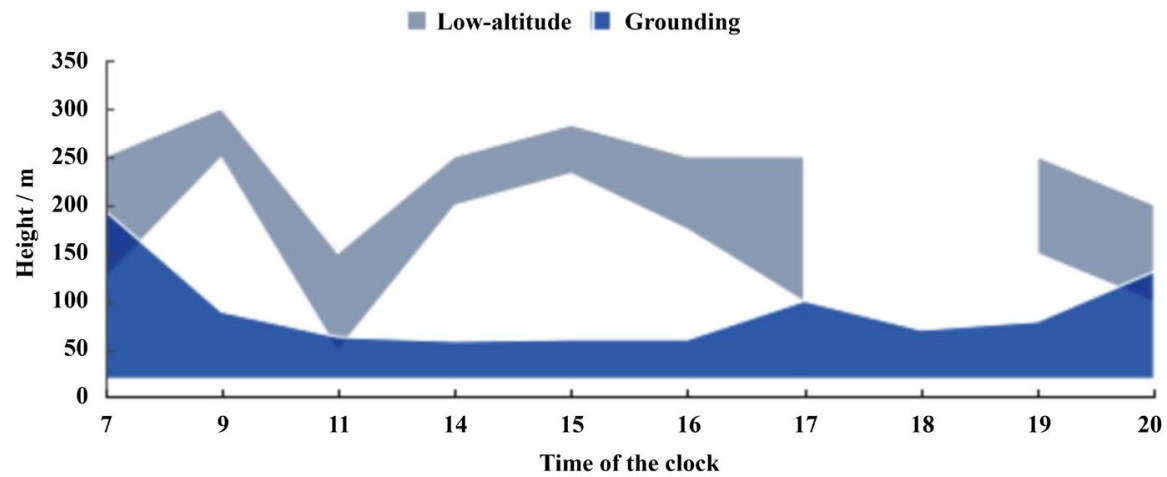

Figure 2. Low-altitude and grounding inversion height timing changes.

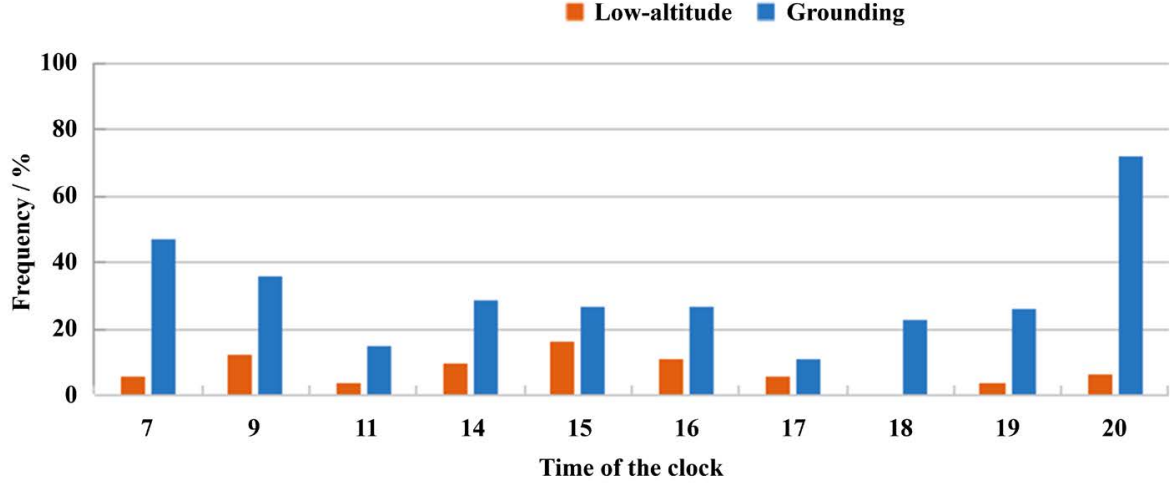

Figure 3. Low-altitude and grounding inversion frequency time distribution. 


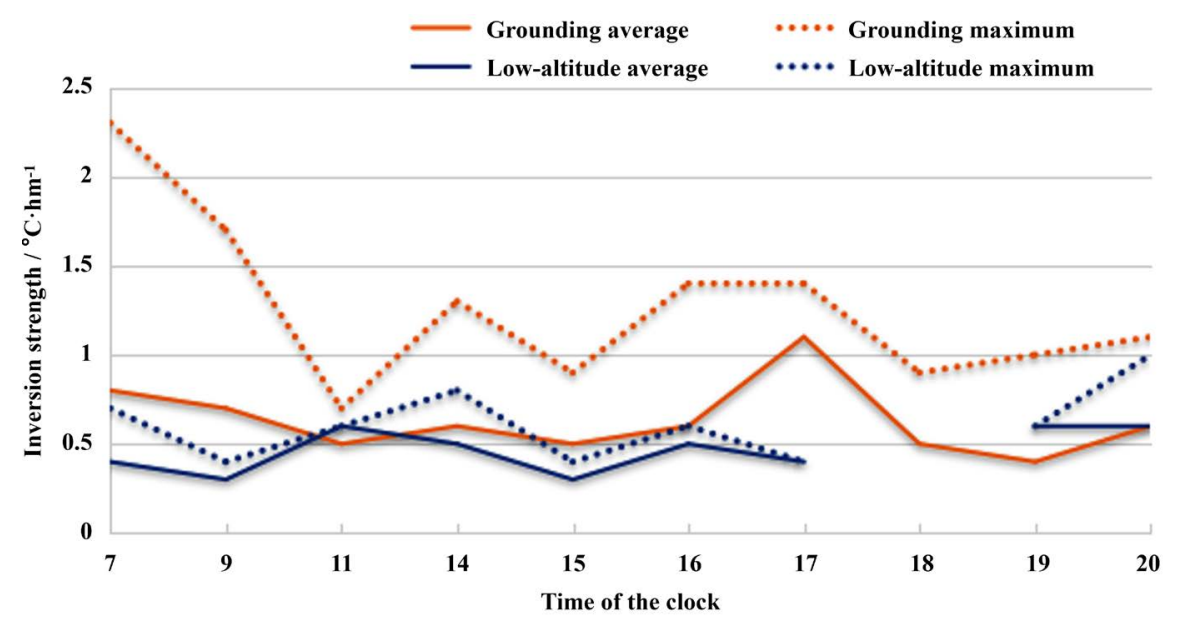

Figure 4. Low-altitude and grounding inversion strength time distribution.

It can be seen from Figures 2-4 that the low-altitude inversion temperature can be seen at other times, the frequency can be $3.7 \%$ to $15.8 \%$, the average intensity is $0.3-0.6^{\circ} \mathrm{C} / \mathrm{hm}$, the average thickness is $50-150 \mathrm{~m}$, and the average bottom height is $50-250 \mathrm{~m}$, maximum strength $0.7^{\circ} \mathrm{C} / \mathrm{hm}$, maximum thickness $150 \mathrm{~m}$. At $15 \mathrm{o}^{\prime}$ clock, the frequency is the highest, but the inversion layer is shallow and the intensity is small. The maximum intensity is $0.4^{\circ} \mathrm{C} / \mathrm{hm}$, the bottom average height is $233 \mathrm{~m}$, and the maximum thickness is only $50 \mathrm{~m}$. At 17 o'clock, only one low-altitude inversion was observed, but the bottom was low and the thickness was large, and 100 - $250 \mathrm{~m}$ was a continuous inversion layer.

Comprehensive analysis, comparing the two inversion time characteristics of the project, the frequency and intensity of grounding inversion are significantly higher than the low temperature inversion. In general, the low-altitude inversion is more likely to occur in the afternoon, and the grounding inversion mainly occurs in the night to the morning (Geels et al., 2007; Zasova et al., 1999). The reason is that the turbulent activity during the day is strong, and the vertical movement easily breaks through the inversion layer to achieve heat exchange between the upper and lower layers, and the grounding inversion is destroyed. The turbulence is easy to form a low-altitude inversion with short duration and low intensity; the ground radiation is strong at night, and the ground temperature is much lower than the high-altitude temperature, forming a grounded inversion temperature.

According to the statistical results of grounding inversion and low-altitude inversion at various times during the observation period, the corresponding examples of the corresponding grounding inversion temperature and low-altitude inversion temperature maximum strength and maximum thickness are found. It was found that during the high temperature observation period during the daytime (9 - 19 o'clock), the height and maximum thickness corresponding to the maximum intensity of the grounding inversion temperature at each time were lower than the outlet height of the air cooling tower $(100 \mathrm{~m})$, which had a very small effect on heat dissipation. At 7 and 20 o'clock, although the maximum 
thickness is higher than the height of the air cooling tower exhaust port, the surface air temperature has dropped at this time, and the inhaled air is lower than the daytime high temperature period, which is conducive to carrying more heat. Although the low-altitude inversion temperature is low and the intensity is small, the maximum intensity and maximum thickness correspond to the height of the bottom of the case, and the height of the air-cooling tower is mostly in the low-altitude inversion height range. Therefore, the maximum intensity during the high temperature period should be considered in the design. The effect of low altitude inversion.

\subsection{Abbreviations and Acronyms}

The top temperature of the inversion temperature is divided into three levels, and the spatial distribution characteristics of grounding inversion and low-altitude inversion at each level during the observation period are statistically analyzed. It can be seen from Figure 5 \& Figure 6 that the grounding inversion temperature occurs below $300 \mathrm{~m}$, the average intensity is $0.6-0.8^{\circ} \mathrm{C} / \mathrm{hm}$, and the maximum intensity is $1.3-2.3^{\circ} \mathrm{C} / \mathrm{hm}$. As the height of the inversion layer increases, the

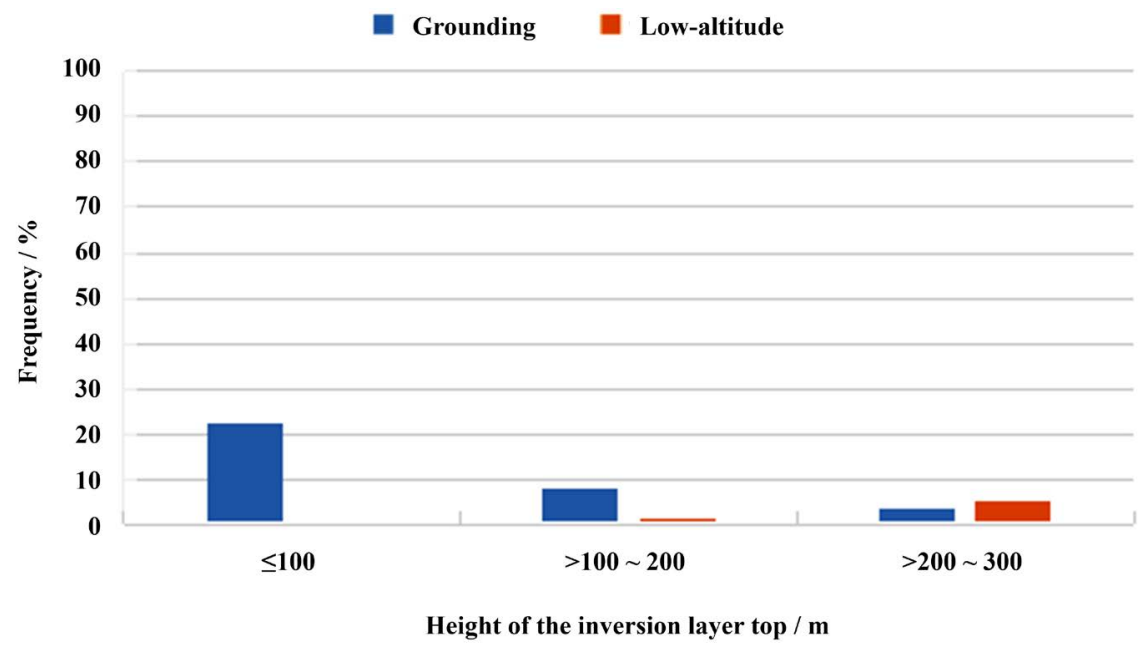

Figure 5. Grounding and low-temperature inversionfrequency at different heights.

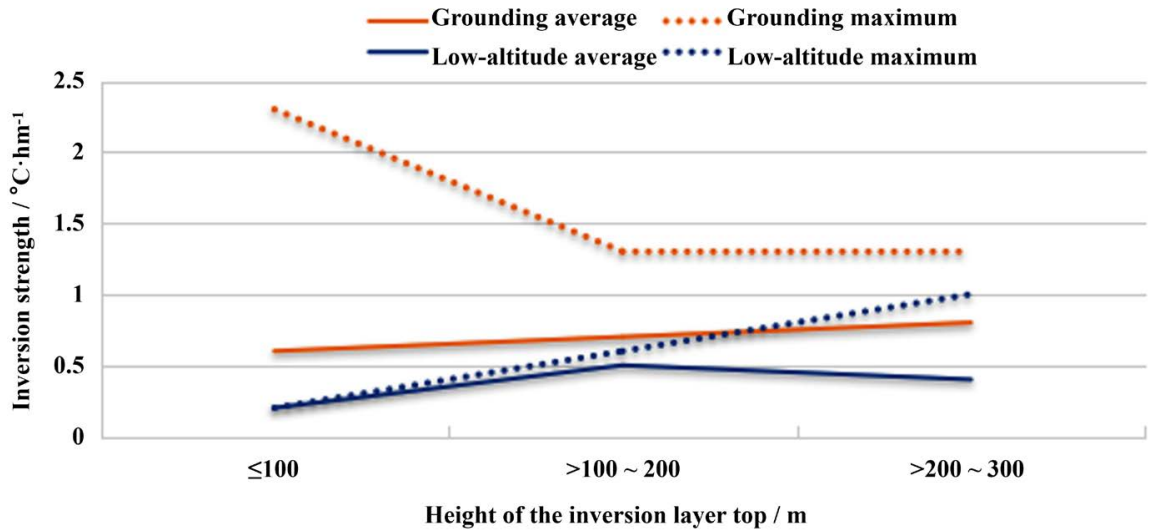

Figure 6. Grounding and low-temperature inversion strength at different heights. 
frequency decreases and the average intensity increases. The grounding inversion frequency with the top height of $100 \mathrm{~m}$ or less is the highest, and the maximum intensity reaches $2.3^{\circ} \mathrm{C} / \mathrm{hm}$.

It can be seen from Figure 5 \& Figure 6 that the low-altitude inversion temperature appears at all levels, and the average intensity is $0.2-0.5^{\circ} \mathrm{C} / \mathrm{hm}$. The top height is $200-300 \mathrm{~m}$, the low-temperature inversion temperature is the highest, the average intensity is $0.4^{\circ} \mathrm{C} / \mathrm{hm}$, the maximum intensity reaches the maximum, $1.0^{\circ} \mathrm{C} / \mathrm{hm}$, and the average thickness is $76.9 \mathrm{~m}$. The low-altitude inversion of the top height between $100-200 \mathrm{~m}$ has the largest average thickness of $83.3 \mathrm{~m}$. The low-altitude inversion of the top height of $100 \mathrm{~m}$ or less has the smallest average thickness of only $50 \mathrm{~m}$. The average height of the low-altitude inversion at a top height of $200 \mathrm{~m}$ or more is $76.9 \mathrm{~m}$. The above characteristics indicate that the low-altitude inversion temperature is dynamically changing, and there is no relatively long-lasting and stable low-altitude inversion.

According to a comprehensive analysis, the frequency of grounding inversion in the summer of the project is greater than the low temperature inversion. With the increase of height, the grounding inversion temperature decreases, the low temperature inversion increases, and the grounding inversion intensity is greater than the low temperature inversion. According to the statistical results of grounding inversion and low-altitude inversion at various levels during the observation period, the examples of the corresponding grounding inversion and low-altitude inversion maximum intensity and maximum thickness are found. It is found that the grounding inversion temperature decreases with height, and the average intensity changes little, but the maximum intensity decreases. The grounding inversion temperature affecting the outlet of the air cooling tower is $11.3 \%$, which accounts for about $1 / 3$ of the total grounding inversion temperature. The low-temperature inversion strength increases with the height of the bottom, and the maximum strength and thickness increase. However, the intensity changes at different height levels are more uniform under average conditions.

\section{Conclusion}

At the same time, the grounding inversion and low-altitude inversion can be observed at the project site. The design of the air-cooled tower needs to fully consider the influence caused by the inverse temperature below $300 \mathrm{~m}$. The grounding inversion temperature and intensity are significantly higher than the low-altitude inversion. The grounding inversion mainly occurs in the night to the morning, and the low-altitude inversion is more likely to occur in the afternoon. The grounding inversion temperature appears every time, the frequency is the highest at 20 o'clock, and the average intensity is maximum at 17 o'clock. At 7 o'clock, the average height, maximum strength and maximum height reached the maximum values of $194.1 \mathrm{~m}, 2.3^{\circ} \mathrm{C} / \mathrm{hm}$ and $300 \mathrm{~m}$, respectively. The low-altitude inversion temperature can be seen in all other times except for 18 o'clock. At 15 o'clock, the frequency is the highest, but the inversion layer is shallow, the bottom is high and the strength is small, the maximum intensity is 
$0.4^{\circ} \mathrm{C} / \mathrm{hm}$, and the average height at the bottom is $233 \mathrm{~m}$. At $17 \mathrm{o}$ 'clock, only one low-altitude inversion was observed, with a low bottom and a large thickness.

Grounding inversion and low-altitude inversion can occur in all layers, and the grounding inversion intensity is greater than the low-altitude inversion. The grounding inversion temperature increases with height, the frequency decreases, and the average intensity increases. The grounding inversion frequency with the top height of $100 \mathrm{~m}$ or less is the highest, and the maximum intensity reaches $2.3^{\circ} \mathrm{C} / \mathrm{hm}$. The low-altitude inversion temperature increases with height, the frequency increases, the top height is between $200-300 \mathrm{~m}$, the average intensity is $0.4^{\circ} \mathrm{C} / \mathrm{hm}$, the maximum intensity reaches $1.0^{\circ} \mathrm{C} / \mathrm{hm}$, and the average thickness is $76.9 \mathrm{~m}$.

\section{Conflicts of Interest}

The authors declare no conflicts of interest regarding the publication of this paper.

\section{References}

Alsamhi, S. H., Ansari, M. S., Ma, O., Almalki, F., \& Gupta, S. K. (2018). Tethered Balloon Technology in Design Solutions for Rescue and Relief Team Emergency Communication Services. Disaster Medicine and Public Health Preparedness, 13, 1-8. https://doi.org/10.1017/dmp.2018.19

Geels, C., Gloor, M., Ciais, P., Bousquet, P., Peylin, P., \& Vermeulen, A. T., et al. (2007). Comparing Atmospheric Transport Models for Future Regional Inversions over Europepart 1: Mapping the Atmospheric $\mathrm{CO}_{2}$ Signals. Atmospheric Chemistry and Physics, 7, 3461-3479. https://doi.org/10.5194/acp-7-3461-2007

Li, Q. H., Zhang, R., \& Wei, D. N. (2011). Analysis of Low Temperature Atmospheric Inversion Characteristics in Taiyuan City. The 28th Annual Meeting of the Chinese Meteorological Society-S7 Urban Meteorological Forecast and Service.

Shen, H. Q., Sun, C. Q., \& Wei, Z. H. (2011). Case Analysis of Atmospheric Pollution Meteorological Observation in Coal Power Engineering. Modern Agricultural Technology, 18, 290-292.

Wang, L. (2014). Low Temperature Inversion Characteristics of Zhengzhou and Its Influence on Smog. Henan Science and Technology, 11, 211-212.

Wylie, D. P., \& Young, J. A. (1979). Boundary-Layer Observations of Warm Air Modification over Lake Michigan Using a Tethered Balloon. Boundary-Layer Meteorology, 17, 279-291. https://doi.org/10.1007/BF00117919

Yabuki, M., Matsuda, M., Nakamura, T., Hayahsi, T., \& Tsuda, T. (2016). A Scanning Raman Lidar for Observing the Spatio-Temporal Distribution of Water Vapor. Journal of Atmospheric and Solar-Terrestrial Physics, 150, 21-30. https://doi.org/10.1016/j.jastp.2016.10.013

Zasova, L. V., Khatountsev, I. A., Moroz, V. I., \& Ignatiev, N. I. (1999). Structure of the Venus Middle Atmosphere: Venera 15 Fourier Spectrometry Data Revisited. Advances in Space Research, 23, 1559-1568. https://doi.org/10.1016/S0273-1177(99)00169-6

Zhou, S. H., Ni, C. J, \& Liu, P. C. (2015). Inversion Characteristics of Atmospheric Boundary Layer in Chengdu Area. Journal of Meteorology and Environment, 31, 108-111. 